\title{
Coughing and choking in motor neuron disease
}

\author{
S Hadjikoutis, R Eccles, C M Wiles
}

\begin{abstract}
Objectives-To assess the frequency and severity of coughing and choking episodes, possible related factors, and their association with chest infections in patients with motor neuron disease (MND). Methods-Thirty seven patients with MND and 23 healthy volunteers were studied. Cough was assessed using a questionnaire and a 3 day diary, and volitional cough quantified by peak cough flow and sound intensity. Other clinical symptoms, smoking habit, affective state, oral secretions, bulbar signs, and quantitative assessments of swallowing and respiratory function were documented.

Results-Patients with MND coughed and choked significantly more often and to a greater degree than the healthy volunteers (26 of 37 patients with MND and 2 of 23 volunteers, $p<0.001)$. Female sex, older age, abnormal speech, reduced swallowing capacity, and low forced vital capacity (FVC)\% predicted were each significantly associated with excessive coughing and choking episodes in patients with MND. Smokers had significantly more severe and prolonged episodes of coughing and choking than non-smokers $(p<0.05)$. Patients with upper motor neuron bulbar signs had a greater tendency to severe and prolonged episodes of coughing and choking than those without $(p<0.05)$. Chest infections were reported only rarely among the patients who coughed and choked.
\end{abstract}

Conclusions-Coughing and choking episodes are common in patients with MND but infrequently associated with overt chest infection. Upper motor neuron bulbar signs may both promote factors (for instance, dysphagia) which trigger cough and reduce volitional capacity to suppress it. (F Neurol Neurosurg Psychiatry 2000;68:601-604)

Keywords: coughing; choking; motor neuron disease; dysphagia

There is no curative treatment available currently for motor neuron disease (MND), and the palliation of symptoms of the disease is of paramount importance. ${ }^{1}$ One of the most distressing of these symptoms commonly reported by patients is coughing and choking. In normal people cough is a distinct phenomenon from choking (the feeling of suffocation or blockage of breathing) but in patients with MND they are difficult to differentiate. There is little information in the literature about the frequency and cause of coughing and choking episodes in patients with $\mathrm{MND},{ }^{2}$ and in particular, whether such symptoms presage an imminent chest infection. The purpose of this study was to assess the severity of these events, to detail related factors, and to clarify how often such patients developed chest infections. Preliminary data were presented previously at a meeting of the Association of British Neurologists'. ${ }^{3}$

\section{Methods}

PATIENTS

Patients with MND (diagnosed according to the El Escorial criteria) ${ }^{4}$ were recruited from the neurology ward, the general neurology clinics at University Hospital of Wales, and the MND clinic at Rookwood Hospital. Healthy volunteers without a history of swallowing, breathing, or neurological disorder were recruited from hospital staff and the general public.

\section{TECHNIQUES}

Patients kept a 3 day diary to list coughing and choking episodes and their association with meals. For each bout of coughing they were asked to indicate severity using a four point scale: $1=$ minor, $2=$ cause breathlessness, $3=$ unable to breath for a time, $4=$ requires assistance or suction device. For each day that patients completed the diary, they were asked to indicate how distressing any coughing and choking episodes had been using a six point scale the limits of which were "extremely distressing" and "no problem". A rough indication of the duration of each episode was also recorded.

Patients were asked to suspend recording during any period when they had an upper respiratory tract infection and to recommence after full recovery. The capacity to volitionally cough was quantified by measuring peak cough flow $^{5}$ and sound intensity. The peak cough flow ( $1 / \mathrm{min}$ ) was measured by asking the patient to volitionally cough into a portable electronic spirometer (MicroLab 3300). The sound intensity of volitional cough was measured by a sound level meter GA208. ${ }^{6}$ This is a portable, battery operated device that contains the appropriate electronics to convert the sound pressure into a meter reading in decibels. Patients were asked to volitionally cough in front of the sound level meter's condenser microphone.

Clinical symptoms, smoking habit, affective state (using the hospital anxiety and depression scale $^{7}$ ), oral secretions, and respiratory function (forced vital capacity (FVC)) were documented. Bulbar signs were measured using a semiquantitative scale, ${ }^{8}$ and swallowing was assessed by a timed test of swallowing. ${ }^{9}$ This timed test provides a reliable and valid numeri- 
Table 1 Clinical characteristics of patients with MND

\begin{tabular}{|c|c|c|c|c|}
\hline & $\begin{array}{l}\text { All MND } \\
\text { patients } \\
(n=37)\end{array}$ & $\begin{array}{l}\text { MND patients with } \\
0-2 \text { coughing episodes } \\
\text { in } 3 \text { days }(n=15) \\
\text { (group 1) }\end{array}$ & $\begin{array}{l}\text { MND patients with } \\
>2 \text { coughing episodes } \\
\text { in } 3 \text { days }(n=22) \\
\text { (group } 2)\end{array}$ & p Value \\
\hline \multicolumn{5}{|l|}{ Sex } \\
\hline Female (\%) & $12(32)$ & $2(13)$ & $10(45)$ & $0.03^{\star}$ \\
\hline Male (\%) & $25(68)$ & $13(87)$ & $12(55)$ & \\
\hline Age $((y)$ mean $(S D))$ & $66(11)$ & $61(12)$ & $70(8)$ & $0.015 \$$ \\
\hline Duration of symptoms ((y) mean (SD)) & $4.0(4.3)$ & $5.0(4.6)$ & $3.6(3.6)$ & $0.36 \$$ \\
\hline $\begin{array}{l}\text { Timed test of swallowing vol/time }((\mathrm{ml} / \mathrm{s}) \% \text { pred mean } \\
(\mathrm{SD}))\end{array}$ & $49(45)$ & $71(48)$ & $33(33)$ & $0.009 \$$ \\
\hline \multicolumn{5}{|l|}{ Bulbar signs } \\
\hline Normal (\%) & $11(28)$ & $6(40)$ & $4(18)$ & $>0.05^{\star}$ \\
\hline $\mathrm{LMN}(\%)$ & $11(28)$ & $4(26)$ & $7(32)$ & \\
\hline $\mathrm{UMN}(\%)$ & $10(27)$ & $5(34)$ & $6(27)$ & \\
\hline $\mathrm{UMN}+\mathrm{LMN}(\%)$ & $5(17)$ & $0(0)$ & $5(23)$ & \\
\hline \multicolumn{5}{|l|}{ Speech } \\
\hline Normal (\%) & $13(35)$ & $9(58)$ & $4(18)$ & $0.02^{\star}$ \\
\hline Abnormal (\%) & $24(65)$ & $6(42)$ & $18(82)$ & \\
\hline FVC \% (pred mean (SD)) & $60(20)$ & $70(22)$ & $56(14)$ & $0.039 \dagger$ \\
\hline \multicolumn{5}{|l|}{ Oral secretions } \\
\hline Normal or dry (\%) & $25(68)$ & $11(73)$ & $14(64)$ & $>0.2^{\star}$ \\
\hline Excess (\%) & $12(32)$ & $4(27)$ & $8(36)$ & \\
\hline \multicolumn{5}{|l|}{ Smoking } \\
\hline No (\%) & $25(68)$ & $11(73)$ & $13(59)$ & $>0.2^{\star}$ \\
\hline Yes $(\%)$ & $12(32)$ & $4(27)$ & $9(41)$ & \\
\hline \multicolumn{5}{|l|}{ Anxiety } \\
\hline No (\%) & $30(81)$ & $12(80)$ & $20(91)$ & $>0.2^{\star}$ \\
\hline Yesł (\%) & 7 (19) & $3(20)$ & $2(9)$ & \\
\hline \multicolumn{5}{|l|}{ Depression } \\
\hline No $(\%)$ & $31(84)$ & $14(93)$ & $19(86)$ & $>0.2^{\star}$ \\
\hline Yes $\ddagger(\%)$ & $6(16)$ & $1(7)$ & $3(14)$ & \\
\hline
\end{tabular}

${ }^{\star} \chi^{2}$ test; $\nmid$ Kruskal Wallis test; $\mathrm{p}$ refers to comparison between groups 1 and 2 ; $\ddagger$ hospital anxiety depression scale $\geqslant 11$.

cal measure of swallowing capacity (measured in $\mathrm{ml} / \mathrm{s}$ ) based on the time taken to drink a known volume of water and expressed in relation to a normal range in age and sex matched subjects: the test may be undertaken repeatedly at home or at the bedside in hospital: such a test provides quite different information from videofluoroscopy.

Variables were assessed for distribution. Comparison of continuous variables between groups (of patients with MND) was made using one way analysis of variance (ANOVA) or Kruskal-Wallis test. The $\chi^{2}$ test was used to test for independence of variables.

The study was approved by the Bro Taf local ethics committee in Cardiff. All patients and volunteers gave consent for the study.

\section{Results}

Thirty seven successive patients with MND (25 men, mean age 66 (range $31-81$ ) years and 12 women, mean age 69 (range 50-80) years) and 23 healthy volunteers ( 13 men, mean age 51 (range 30-70) years and 10 women, mean age 57 (range 41-67) years) were assessed. Only one of the patients with MND had chronic primary pulmonary disease (emphysema); he had a low sensitivity to cough in relation to upper respiratory tract infections. He was taking salbutamol ( $5 \mathrm{mg}$ four times daily) via an inhaler. The clinical characteristics of the patients with MND are shown in table 1.

Two out of 23 healthy volunteers coughed over 3 days compared with 26 of 37 patients with MND (Kruskal-Wallis test, $\mathrm{p}<0.001$, table 2). The two healthy volunteers coughed briefly once or twice only. Of the patients with MND the number of episodes varied from 1-50 (table 2) and total duration of coughing from $<2$ minutes to 45 minutes over 3 days (table 2). Ten $(27 \%)$ patients with MND described episodes as being moderately or very
Table 2 Total number and duration (min) of coughing and choking episodes in 3 days

\begin{tabular}{lll}
\hline $\begin{array}{l}\text { Coughing and choking } \\
\text { epidodes in } 3 \text { days }\end{array}$ & $\begin{array}{l}\text { Healthy volunteers } \\
(n=23)\end{array}$ & $\begin{array}{l}\text { MND patients } \\
(n=37)\end{array}$ \\
\hline Total number: & & \\
0 & 21 & 10 \\
$1-2$ & 2 & 5 \\
$3-9$ & 0 & 11 \\
$10-30$ & 0 & 9 \\
$31-50$ & 0 & 2 \\
Total duration ${ }^{\star}(\mathrm{min}):$ & & \\
0 & 21 & 11 \\
$<2$ & 2 & 7 \\
$2-9$ & 0 & 8 \\
10 & 0 & 1 \\
15 & 0 & 2 \\
20 & 0 & 1 \\
45 & 0 & 1
\end{tabular}

${ }^{\star}$ Only 31 patients with MND recorded the duration of coughing and choking episodes on the 3 day diary.

distressing, whereas $23(73 \%)$ patients experienced slight or no distress. Twelve (32\%) patients recorded breathlessness (severity scale $=2$ ) or inability to breath (severity scale $=3$ ) during the episodes. Eight $(22 \%)$ patients recorded episodes of coughing or choking only during meals. Eighteen (49\%) patients had episodes of coughing or choking not associated with meals: of those, two did not record any episodes during meals over 3 days and nine $(24 \%)$ recorded that sometimes they woke up at night coughing or choking.

Patients with MND were divided into two groups based on the range of coughing and choking in healthy volunteers: those with $0-2$ coughing episodes over 3 days (group 1) and those with $>2$ episodes (group 2, table 1). Patients within group 2 had a greater tendency to be women and to be older, to have an abnormal speech, a slower timed test of swallowing, and a lower FVC\% predicted than those patients within group 1 (table 1). Although smoking habit was not associated with number of episodes, smokers had significantly more 
Table 3 Quantification of volitional cough in patients with MND

\begin{tabular}{llll}
\hline & $\begin{array}{l}\text { MND patients with } \\
\text { 0-2 coughing } \\
\text { episodes in 3 days } \\
(n=15) \text { (group 1) }\end{array}$ & $\begin{array}{l}\text { MND patients with } \\
\text { episodes in 3 days } \\
(n=22) \text { (group 2) }\end{array}$ & p Value \\
\hline Peak cough flow ((1/min) mean (SD)) & $281(167)$ & $156(124)$ & $0.016^{\star}$ \\
Cough intensity ((Db) mean (SD)) & $84(6)$ & $68(34)$ & $0.112^{\star}$ \\
\hline
\end{tabular}

${ }^{\star}$ Kruskal Wallis test. with the presence of excessively brisk laryngeal closure reflexes then the reflexes may be triggered at a lower threshold than usual, and enhance the risk of upper airway obstruction (feeling of choking). It might be expected that inefficient pharyngeal clearance with pooling of saliva or detritus in the valleculae or pyriform fossae, and premature oral loss of food material could act as provocative factors in triggering episodes: whether oesophageal reflux also contributes at night for instance is unclear. Furthermore, bilateral bulbar involvement of upper motor neurons might impede the ability to suppress cough (analogous to laughing, crying, or breathing with pseudobulbar palsy) leading to more frequent or protracted bouts once triggered.

Smokers tended to have more severe and prolonged attacks of coughing and choking than non-smokers. Smoking can cause airway inflammation, and the release of specific inflammatory products (for example, bradykinin) may cause hyperactivity of the reflex cough. Cessation of smoking may be useful in those patients with significant episodes of coughing and choking.

Patients with coughing and choking episodes had a tendency to have lower volitional respiratory and cough indices (FVC, peak cough flow, and cough intensity) than those without. However, volitional control of respiration can be impaired by corticospinal tract lesions, ${ }^{10}$ as may occur in MND, and therefore FVC measurements give an incomplete picture of respiratory function in these patients: tests of nonvolitional activation-for example, using $\mathrm{CO}_{2}$ rebreathing or reflex cough activation-might be used in principle. We have not used non-volitional respiratory tests in this study. Similarly, the measurements of cough amplitude and intensity used in this study are based on volitional activation; however, there is evidence that there are separate pathways for the volitional and reflex cough ${ }^{11}$ which could be selectively affected by MND. Coughing and choking episodes due to upper airway irritation might be more likely to be initiated by the reflex cough than the volitional cough. An independent measure of cough intensity in response to reflex cough triggering (analogous to stimulation of respiration by increased arterial $\mathrm{CO}_{2}$ ) would be of value. Selective involvement of pyramidal pathways to respiratory muscles and tongue can be demonstrated using transcranial magnetic stimulation. ${ }^{12}$

Anxiety may exacerbate or trigger coughing and choking attacks in patients with MND, and sometimes anxiolytic agents (for example, sublingual lorazepam) are prescribed to prevent or stop these episodes. However, this study showed that anxiety was not specifically associated with the number, severity, or duration of episodes and in this context care is necessary in distinguishing symptoms of anxiety due to acute hypoxia from those due to psychological causes.

Only two patients who recorded coughing and choking attacks had had an overt chest infection since the diagnosis of MND. However, both of them were heavy smokers and one had other 
significant medical problems (diabetes, emphysema, prostate cancer) which could have contributed to the pathogenesis of the chest infections. We have not systematically used any tests (for example, videofluroscopy) to assess aspiration in those patients who coughed or choked. However, this study showed that, overall, coughing and choking episodes are rarely associated with aspiration pneumonia. Whether, in this context, pneumonia is associated with frequent minor or subclinical aspirations or larger single events or the aspiration of infected material is unclear. Recent studies support the view that factors other than simple mechanical aspiration should be considered in the pathogenesis of aspiration pneumonia (for example, oral/dental status, host resistance, pulmonary clearance, smoking). ${ }^{13}$

In conclusion, coughing and choking episodes are clinically underdiagnosed in MND; the results of the present study provide information about the incidence and possible factors which are important in provoking these episodes. Upper motor neuron bulbar involvement is likely to be an important factor in triggering cough (via dysphagia) and in reduced ability to suppress cough once triggered. Reduction of exogenous stimuli likely to trigger laryngeal closure reflexes and medical suppression of such brisk reflexes are potential avenues of treatment for these distressing symptoms.
$\mathrm{S} \mathrm{H}$ is supported by a bequest for MND research and a Grant from Schering AG.

1 Borasio GD, Voltz R. Palliative care in amyotrophic lateral sclerosis. F Neurol 1997;244(suppl 4):S11-17.

2 Newrick PG, Langton-Hewer R. Motor neurone disease: can we do better? A study of 42 patients. BMF 1984;289:539-42.

3 Hadjikoutis S, Eccles R, Wiles CM. Coughing and choking in motor neuron disease [abstract]. F Neurol Neurosurg Psychiatry 1999;67:843.

$4 \mathrm{El}$ escorial revisited: revised criteria for the diagnosis of amyotrophic lateral sclerosis. A consensus conference held at Airlie House, Warrington, Virginia, April 1998. www.wfnals.org/ Articles/elescorial

5 Bach JR. Amyotrophic lateral sclerosis: predictors for prolongation of life by noninvasive respiratory aids. Arch Phys Med Rehabil 1995;76:828-32.

6 Freestone C, Eccles R. Assessment of antitussive efficiency of codeine in cough associated with common cold. F Pharm Pharmacol 1997;49:1045-9.

7 Zigmond AS, Snaith RP. The hospital anxiety and depression scale. Acta Psychiatr Scand 1983;67:361-70.

8 Hughes TAT, Wiles CM. Palatal and pharyngeal reflexes in health and motor neurone disease. F Neurol Neurosurg Psyhealth and motor neur
chiatry 1996;61:96-8.

9 Hughes TAT, Wiles CM. Clinical measurement of swallowing in health and in neurogenic dysphagia. $Q \mathcal{F}$ Med 1996; 89:109-16.

10 Howard RS, Newsom-Davis J. The neural control of respiratory function. In: R Crockard, R Hayward, JT Hoff, eds. Neurosurgery: the scientific basis of clinical practice. 2nd ed. Oxford, UK: Blackwell, 1992:318-36.

11 Hutchings HA, Morris S, Eccles R, et al. Voluntary suppresion of cough induced by inhalation of capsaicin in healthy volunteers. Respir Med 1993;87:379-82.

12 Urban PP, Hopf HC, Connemann B, et al. The course of cortico-hypoglossal projections in the human brainstem: functional testing using transcranial magnetic stimulation. Brain 1996;119:1031-8.

13 Langmore SE, Terpenning MS, Schork A, et al. Predictors of aspiration pneumonia: how important is dysphagia? Dysphagia 1998;13:69-81. 